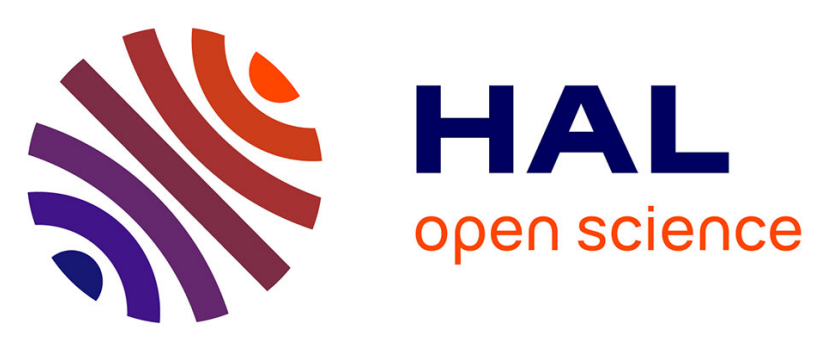

\title{
Prominence of Using Betalain and Cubebin as Natural Dye Sensitizers for the Design of Eco-Friendly DSSC's
}

S. Ranjitha, V. Aroulmoji, R. Lavanya Dhevi, G. Rajarajan, S. Gnanendra

\section{To cite this version:}

S. Ranjitha, V. Aroulmoji, R. Lavanya Dhevi, G. Rajarajan, S. Gnanendra. Prominence of Using Betalain and Cubebin as Natural Dye Sensitizers for the Design of Eco-Friendly DSSC's. International journal of advanced Science and Engineering, 2018, 4 (4), pp.726. 10.29294/IJASE.4.4.2018.726-736 . hal-03093611

\section{HAL Id: hal-03093611 \\ https://hal.science/hal-03093611}

Submitted on 20 Jan 2021

HAL is a multi-disciplinary open access archive for the deposit and dissemination of scientific research documents, whether they are published or not. The documents may come from teaching and research institutions in France or abroad, or from public or private research centers.
L'archive ouverte pluridisciplinaire HAL, est destinée au dépôt et à la diffusion de documents scientifiques de niveau recherche, publiés ou non, émanant des établissements d'enseignement et de recherche français ou étrangers, des laboratoires publics ou privés. 


\title{
Prominence of Using Betalain and Cubebin as Natural Dye Sensitizers for the Design of Eco-Friendly DSSC's
}

\author{
S. Ranjitha ${ }^{1}$, V. Aroulmoji ${ }^{2}$, R. Lavanya Dhevi ${ }^{1}$, G. Rajarajan ${ }^{3}$, S. Gnanendra ${ }^{2}$ \\ ${ }^{1}$ Department of Physics, Velalar College of Engineering and Technology, Thindal, Erode - 638012, Tamil Nadu, India \\ ${ }^{2}$ Center for Research and Development, Mahendra Engineering College, \\ Mallasamudram - 637503, Tamil Nadu, India \\ ${ }^{3}$ Department of Physics, Hindustan Institute of Technology and Science, Chennai-603103, Tamil Nadu, India
}

\begin{abstract}
Globally, the steady increase in 5\% of energy per year has urged the need of alternative sources of renewable energy and has become a top challenge. The PV technology has become the most promising technology in harvesting the solar-energy. The use of natural pigments has become a viable alternative to expensive and rare Ruthenium dyes because of its low cost, easy attainability, abundance in supply of raw materials and no environment threat. In this paper, we investigate the performance of Dye Sensitized Solar Cells (DSSCs) based on natural dyes extracted from Indian medicinal plants. Herein, Cubebin and Betalain dyes are extracted from fresh Ocimum tenuiflorum and Piper nigrum. FT-IR, FT-Raman, Photoluminescence and UV-visible light absorption characteristics of the dyes are used to identify the characteristic peaks of the extracted dyes. Features of the electronic absorption spectrum in the visible and near-UV regions were assigned based on TD-DFT calculations. These dyes are used as photo sensitizer for fabrication of $\mathrm{TiO}_{2}$ photo-anode based dye sensitized solar cells (DSSCs). The photo-voltaic characteristics of the developed DSSCs are measured under simulated solar light. The solar to electric conversion efficiencies for the cubebin and betalain and mixed dye based solar cells are estimated as $0.39 \%$ and $0.38 \%$ respectively. The highest conversion efficiency for natural photo sensitizers based solar cell is attributed due to the absorption of wider range of solar spectrum.
\end{abstract}

KEYWORDS: DSSC, Energy, Solar Cells, Betalain, Cubecin, Photovoltaic, Ocimum tenuiflorum, Piper nigrum

\section{INTRODUCTION}

The research on solar cells has emerged as an alternative source of energy due to its emphasis over the usage of burning fossil fuels which has drastic harmful influence to the environment. Solar cells make use of inexhaustible sunlight as a free source of energy. The development of efficient solar cells will decrease mankind's dependence on fossil fuels that can significantly protect our natural resources. The research on solar cells made its impact as a vital technology among the various renewable sources of energy [1-2]. Solar cells based on the single silicon crystals were the first generation devices that evidenced the highest photon to current conversion efficiency. The high cost of production and installation of first generation solar cells make various researchers introduce the second generation solar cell devices made-up of semiconductor thin films. The unsatisfactory efficiency challenges of the second generation solar cells has led the path to the usage of pigments in the third generation solar cells popularly known as Dye sensitized solar cells (DSSCs). These devices are similar to plant photosynthesis that mechanizes the energy from the absorbed sunlight [37].

A dye-sensitized solar cell is usually composed of a dye capped nano-crystalline porous semiconductor electrode, a metal counter electrode, and a redox electrolyte mediating electron transfer processes that occurs in the cell. The performance of the cell primarily depends on the material and the quality of the semiconductor electrode and naturally extracted or synthesized stable sensitizer dyes. Even though several wide band-gap metal oxide semiconductors are employed in the DSSCs, $\mathrm{TiO}_{2}$ and $\mathrm{ZnO}$ were the most predominantly and successfully used semiconductors [8-10].

The sensitizer plays a key role in absorbing light. Today, Ru (II) polypyridyl complexes were reported to obtain the highest efficiency. Unfortunately, the paucity of $\mathrm{Ru}$ metal and the difficulties in the ruthenium complex preparation have made the DSSCs as most expensive solar cells. To design the low-cost and good stability DSSCs, the search for potential alternative metal complex sensitizers urge to evaluate various organic dyes and natural dyes that were extracted from plants to explore their possibilities as photo-sensitizers. However, these dyes have been fraught with complications like synthetic routes and low yield. On the other hand, the natural dyes found in flowers, leaves, and fruits of plants can be extracted by simple procedures and can be employed in DSSCs. The natural dyes have advantages with resemblance in functionalities of organic dyes and their easy availability, non-toxicity, complete biodegradability and temperature compatibility [11-14].

Several Natural dyes namely tannin, carotene, anthocyanin, Betalain and chlorophyll have been extensively investigated as sensitizers in dyesensitized solar cells [15-17]. 
Solar cells are the main photo-devices that achieve the conversion of light energy into electrical energy. In particular, the solar cells based on photosynthesis principle of plants and algae, have great potential for the development of stable DSSCs. An efficient solar cell sensitizer should demonstrate i) strong adsorption to the semiconductor surface through anchoring groups, ii) intense absorption in the visible part of the spectrum, iii) proper energy level alignment of dye excited state and the conduction band edge of the semiconductor, as well as the redox level of the electrolyte and the ground state of the dye, iv) fast charge transfer from the dye to the substrate, with low loss of photoelectrons, and v) electrochemical and thermal stability. In the attempt to find dyes satisfying these requirements, a large number of different molecules have been synthesized and characterized. The extraction and purifications of new dyes from plants and other materials are time and resource consuming. In spite of the importance, the computational studies were undertaken to evaluate the efficiency of the compounds as a promising alternative analysis. The interest for dye modeling and for more complex dye-substrate computational studies has been steadily increasing [18-23]. Achieving accurate results is challenging because of the size of the system, which in many cases consists of a relatively large number of atoms. In this context, density functional theory (DFT) and time dependent DFT (TD- DFT) methods have been applied to large molecules with reasonable accuracies of a few tenths of an $\mathrm{eV}$, allowing for the description not only for the absorption spectrum of the dye but also for the more complex system consisting of the dye and the $\mathrm{TiO}_{2}$ clusters. The dye bonding on the nanoparticle, the alignment of the energy levels of the two sub-systems, the transfer of the electron from the dye to the cluster can be successfully calculated by means of a DFT approach (24).

In this paper, we report the performance of dyes extracted from the leaves of siddha medicinal plants such as Ocimum Tenuiflorum and Piper Nigrum. The fabrication and electro- optical characterization of DSSCs by using Betalains and Cubebin as $\mathrm{TiO}_{2}$ sensitizers were reported. Based on theoretical calculations the absorption onto the substrate, the matching of the absorption spectra, the energy level alignment, Photo luminescence properties and the charge transfer were discussed and the pigments were emphasized as sensitizers by comparing with

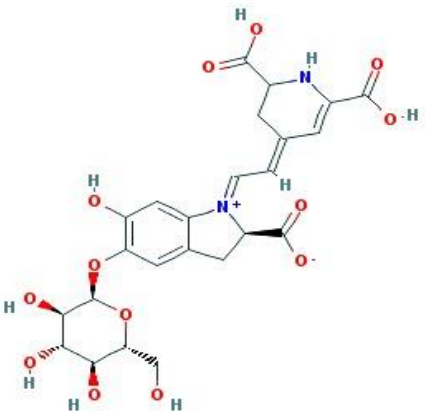

experimental data. To the best of our knowledge, this is the first report on the usage of Betalains and Cubebin dyes as sensitizers for $\mathrm{TiO}_{2}$ based dyesensitized solar cells (DSSCs).

\section{EXPERIMENTAL METHODS}

The basic chemical structure of the pigment Betalain extracted from Ocimum Tenuiflorum and the cubebin pigment extracted from Piper Nigrum were shown Figure.1.

\section{Preparation of Natural Photosensitizers}

The medicinal plants of Ocimum tenuiflorum and Piper nigrum were collected from Kolli hills of Salem, Tamilnadu, India. The leaves were washed several times with distilled water to remove the dust particles and the residual moisture was removed under sun-dried condition. The dried leaves were crushed using mortar and pestle. The crushed powder was mixed with ethanol and the solution is left undisturbed in dark at room temperature. After one week, the residual parts were filtered out and the resultant is used as dye solutions.

\section{Cell Assembly}

The $\mathrm{TiO}_{2}$ porous film electrode was prepared by using the sol-gel method, starting from the commercial Titanium (IV) oxide, anatase, nanopowder $<25 \mathrm{~nm}$, from Sigma-Aldrich. The pure $\mathrm{TiO}_{2}$ paste was prepared by mixing $1 \mathrm{~g}$ of the commercial P25 $\mathrm{TiO}_{2}$ powder (Degussa) with $0.1 \mathrm{ml}$ of acetyl acetone, $0.4 \mathrm{ml}$ of Triton X-100, and $0.2 \mathrm{~g}$ of polyethylene glycol in $5 \mathrm{ml}$ of a mixture of water and ethanol. A conductive glass sheet of $1.5 \mathrm{~cm}^{2}$ was immerged in acetone for $48 \mathrm{~h}$ to remove impurities. A plastic adhesive tape was fixed on the four sides of conductive glass sheet to restrict the thickness and the area of about $1.1 \mathrm{~cm}^{2}$ of $\mathrm{TiO}_{2}$ film was prepared by spreading the $\mathrm{TiO}_{2}$ paste onto the conductive glass by using a glass rod. Finally, the glass sheet was inserted at $450{ }^{\circ} \mathrm{C}$ for 30 minutes and cooled to a temperature of $80-90{ }^{\circ} \mathrm{C}$, the conductive glass of solidified $\mathrm{TiO}_{2}$ was immerged in dye sensitizer alcohol solution for 48 hours to absorb the dye on $\mathrm{TiO}_{2}$ porous film adequately, the other impurities were washed up with anhydrous ethanol and dried in moisture-free air.

Figure 1: The 2D chemical structure of the pigments extracted from Ocimum tenuiflorum and Piper nigrum. a. Betalain b. Cubebin

Ranjitha et al., 
After that, a $\mathrm{TiO}_{2}$ porous film electrode was prepared. Platinum coated FTO glass was used as electrode, followed by drying at $400^{\circ} \mathrm{C}$ for 30 minutes. The electrolyte solution for DSSCs was prepared by dissolving $\mathrm{KI}(0.5 \mathrm{M})$ and $\mathrm{I} 2(0.05 \mathrm{M})$ in mixed solvents of ethylene glycol and acetonitrile $(4: 1$ in the volume ratio). The iodide electrolyte solution was placed at the edges of the plates. The liquid was drawn into the space between the electrodes by capillary action. Two binder clips were used to hold the electrodes together.

\section{Characterization and Measurements}

The photo anodes were characterized by using a UVVisible Spectrophotometer (UV-2550, Shimadzu), a Field Emission Scanning Electron Microscope equipped by an energy dispersive X-ray analyzer (FESEM-EDX, JEOL, JSM-6400), and a BET surface area analyzer (Autosorb-1, Quanta chrome). The photoluminescence (PL) spectra of the samples were analyzed with a Fluorescence Spectrophotometer (Hitachi F-4500FL Spectrophotometer, Japan).The photovoltaic properties of the prepared DSSCs, i.e. short circuit current $\left(\mathrm{J}_{\mathrm{sc}}\right.$ in $\left.\mathrm{mA} / \mathrm{cm}^{2}\right)$, open circuit voltage $\left(\mathrm{V}_{\mathrm{Oc}}\right.$ in $\left.\mathrm{mV}\right)$, fill factor $(\mathrm{FF})$, and efficiency ( $\eta$ in \%) were determined from the I-V curve obtained by using a LOT-Oriel solar simulator (Model LS0100- 1000, 300W Xe Arc lamp Power SupplyLSN251 equipped with AM 1.5 filter, $100 \mathrm{~mW} / \mathrm{cm}^{2}$ ) respectively, with 0.5 and $1 \mathrm{~cm}^{2}$ of illuminated active area.

\section{Theoretical Studies}

The molecular structures of Betalain and cubebin were studied by using Gaussian 9 and were optimized. The Density Functional Theory (DFT) studies were carried out with the B3LYP exchange-correlation functional and the 6-31G (d) basis set. The stability of optimized structures and zero-point corrections on the total energies were obtained by performing vibrational analysis. Using the TD-DFT, the molecular orbitals and electronic transitions were calculated in solvent (acetonitrile) by employing the polarizable continuum model (PCM) with the same B3LYP functional. The basis sets on the heavier atoms were augmented by diffuse functions via $6-31+G(d)$ for better evaluation of electronic states.

\section{RESULTS AND DISCUSSION}

The absorption spectra of dyes betalain and cubebin from Ocimum tenuiflorum and Piper Nigrum ethanol extract were shown in Figure.2 (a,b).

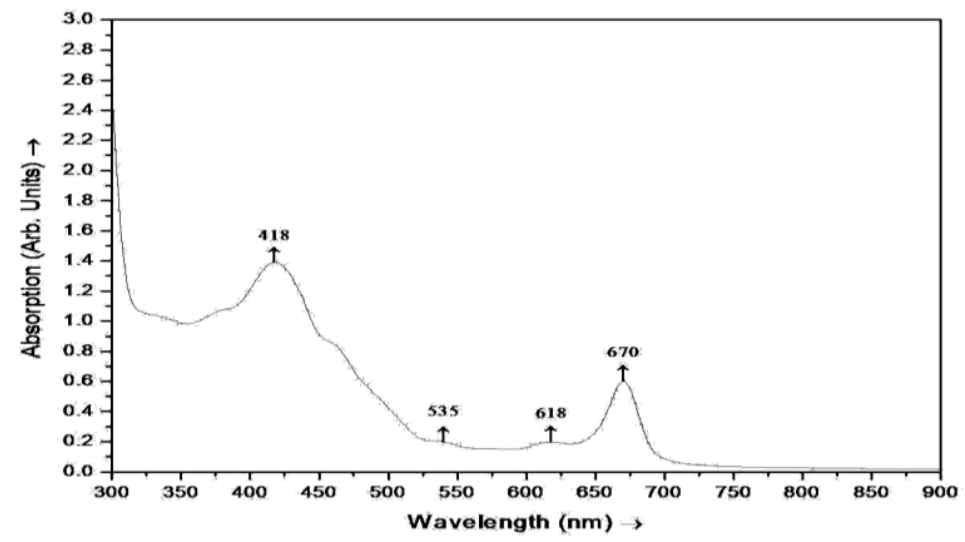

Figure.2 (a): The absorption spectra of dyes from medicinal plants a. betalain dye from Ocimum tenuiflorum

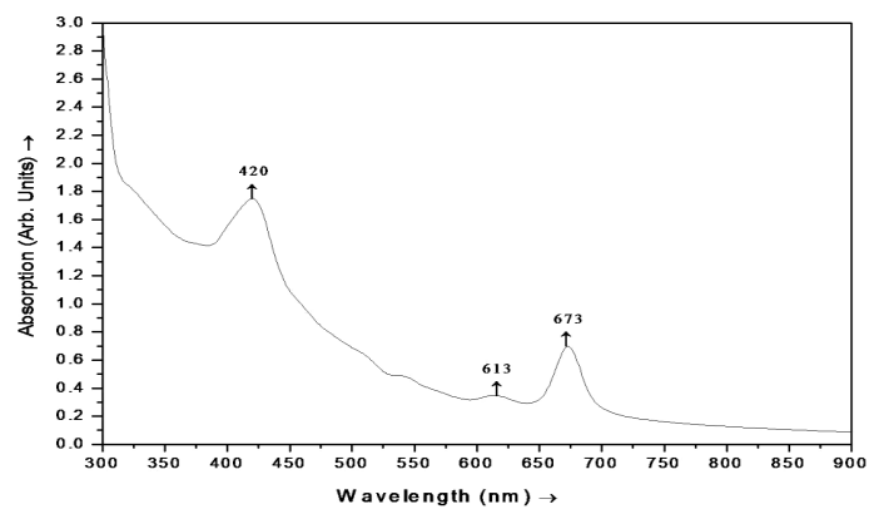

Figure.2 (b): The absorption spectra of dyes from medicinal plants b. Cubebin dye from Piper nigrum Ranjitha et al., 
From the absorption spectra, we have evidenced that the dyes used in the study absorb the light in the visible spectrum that satisfies the primary criteria for their use as sensitizers in DSSCs [24-26]. To be more specific, cubebin extract from Piper nigrum exhibited the broad absorption band in the range of 420-673 $\mathrm{nm}$ and besides showed a sharp absorption peak at $670 \mathrm{~nm}$. Both the dyes, Betalain and Cubebin exhibited the common peak at $670 \mathrm{~nm}$ which is in consideration with the characteristic absorption band of chlorophyll. Piper nigum absorbs in the wide range of $410-600 \mathrm{~nm}$ with an absorption peak at $420 \mathrm{~nm}$. The differences and variations in the absorption characteristics of dyes can be attributed to the different colors of the extracts due to respective pigments present in them.

\section{Photoluminescence of Green Sensitizers}

To recall photoluminescence is a process in which a chemical compound absorbs a photon (electromagnetic radiation), thus transitioning to a higher electronic energy state, and then radiates a photon back out, returning to a lower energy state. Ultimately, available chemical energy states and allowed transitions between states (and therefore wavelengths of light preferentially absorbed and emitted) are determined by the rules of quantum mechanics [27]. In this respect, there may be a correlation between the phenomenon of photoelectron emission and the photoelectric property in a natural dye based DSSC system. Figure 3 shows the emission intensity of dye Betalain extracted from Ocimum tenuiflorum and Cubebin from Piper nigrum.

The emission intensity of the dye namely betalain from Ocimum tenuiflorum has exhibit PL intensity of 672.5 $\mathrm{nm}$ and $870 \mathrm{~nm}$ and cubebin from Piper nigum. In general, the PL intensity increases with increasing number of emitted electrons resulting from recombination between excited electrons and holes. Particularly, the PL intensity decreases more in the presence of a metal that can capture excited electrons and exhibit conductivity, via the relaxation process. Both of the compounds exhibit very good absorption and Photoluminescence property.

\section{Theoretical Analysis of FT-IR and FT-Raman Spectra of Photosensitizers}

The theoretically predicted FT- IR and FT-Raman spectra using B3LYP/6-311 G $(\mathrm{d}, \mathrm{p})$ method and the observed experimental FT-IR and FT-Raman spectra were observed in the range of $4000 \mathrm{~cm}^{-1}$ to $500 \mathrm{~cm}^{-1}$ are shown in Figure 4(a)and (b). The respective FT-IR spectra and FT-RAMAN spectra were recorded in the range from 4000 to $400 \mathrm{~cm}^{-1}$.

The close examination of the spectra reveals that they exhibit broad absorption frequency in the range $4000 \mathrm{~cm}^{-1}$ to $500 \mathrm{~cm}^{-1}$ with a wide and strong band which attributed to the $-\mathrm{OH}$ stretching and due the wide variety of hydrogen bonding between $\mathrm{OH}$ groups. The molecule Betalain exhibits a sharp peak at 2000 $\mathrm{cm}^{-1}$ and Cubebin shows peak around $3744 \mathrm{~cm}^{-1}$ associated with the symmetric and asymmetric $-\mathrm{C}-\mathrm{H}-$ stretching vibrations of $\mathrm{CH}$ and $\mathrm{CH}_{3}$ groups. The signal characteristics bands of $\mathrm{C}=\mathrm{O}$ (carbonyl) stretching vibration at $1600-1750 \mathrm{~cm}^{-1}$ can also be observed due to presence of some aromatic esters. Hence, the IR spectra of extracts contains band that can be assigned due to the coloring components found in the extracts. Betalain contains methyl groups and cubebin containing $\mathrm{C}-\mathrm{H}$ groups are generally referred to as electron donating substituent in the aromatic ring system. Absorption arising from $\mathrm{C}-\mathrm{H}$ stretching in the alkenes occur in the region $3000-2840 \mathrm{~cm}^{-1}$. The lowering of the wave numbers from the normal values is due to the intermolecular charge transfer (ICT) from the dimethyl group to the hydroxyl group via $\pi$ conjugation system.

The changes in intensity of the $\mathrm{CH}_{3}$ stretching mode are also due to the influence of electronic effects resulting from hyper conjugation of methyl group with nitrogen atom and the aromatic ring system. Thus the hyper conjugation of methyl group, causing changes in intensity in IR, clearly indicates that methyl hydrogen is directly involved in the donation of electronic charge. The asymmetric and symmetric bending vibrations of methyl group normally appear around 1446 and 1375 $\mathrm{cm}^{-1}$ respectively. The relatively large value of intensity in IR and Raman wave numbers of the rocking modes suggests the presence of hyper conjugation. The twisting and torsion vibrations are identified below $503 \mathrm{~cm}^{-1}$, which are also supported by the computed wave numbers.

The ring modes which are found to be active in both IR and Raman spectra enable the Betalain molecule to be an effective $\pi$ conjugation system. Because of the existence of one directional charge transfer from the donor to the acceptor through the single-double bond conjugated path induces large variations of both the molecular dipole moment and the molecular polarizability during the same vibrations, thus gaining the activity of both IR and Raman at the same time. The simultaneous activation of IR and Raman ring modes also supports the charge transfer interaction between $\mathrm{CH}_{3}$ and the Benzene ring which also plays an important role in the DSSC activity.

\section{Electronic Structures and Electrochemical Properties}

According to the intra-molecular electron transfer mechanism of dyes in the DSSCs, the highest occupied molecular orbital (HOMO) and lowest unoccupied molecular orbital (LUMO) energy levels of the dye should be lower and higher, respectively, than that of electrolyte and conduction band of semiconductor (TiO2). The electron distribution of HOMO is mainly located in the electro-donor to the $\pi$-conjugated linker while subjecting to sun light irradiation, and the electron transfer proceeds from the electron-donor to the electron-acceptor through the $\pi$ - conjugated linker. The electron distribution of LUMO is delocalized in electron acceptor to the $\pi$-conjugated linker and it could inject the electron from the excited dye to the conduction band of semiconductor.

Theoretically, the dye absorbs photon from the sun light and result in broad band absorption extended from visible to IR region [28-29]. The electron-donating 


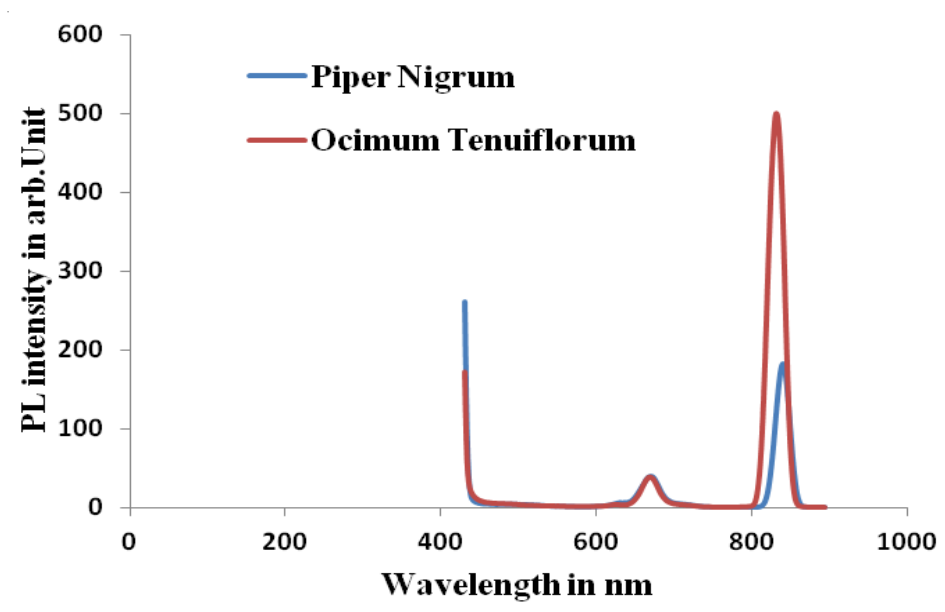

Figure 3: Photoluminescence Spectra for Green Sensitizers
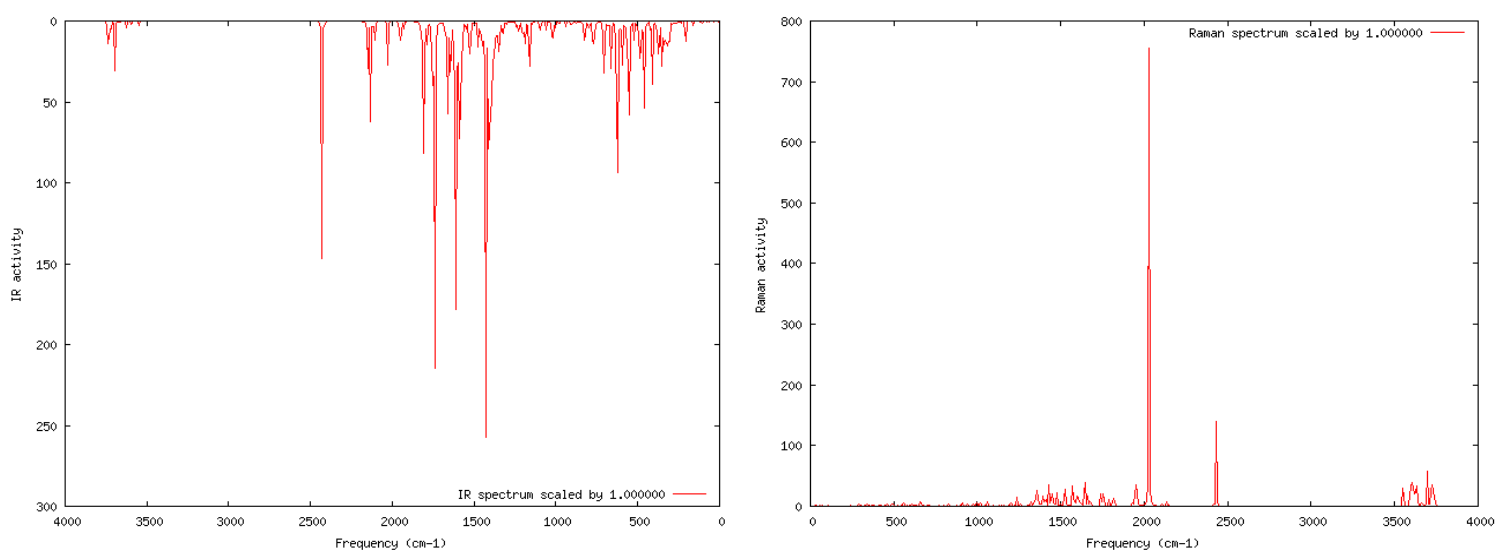

Figure 4 (a) Theoretical FT-IR and FT-Raman Spectra of Betalain
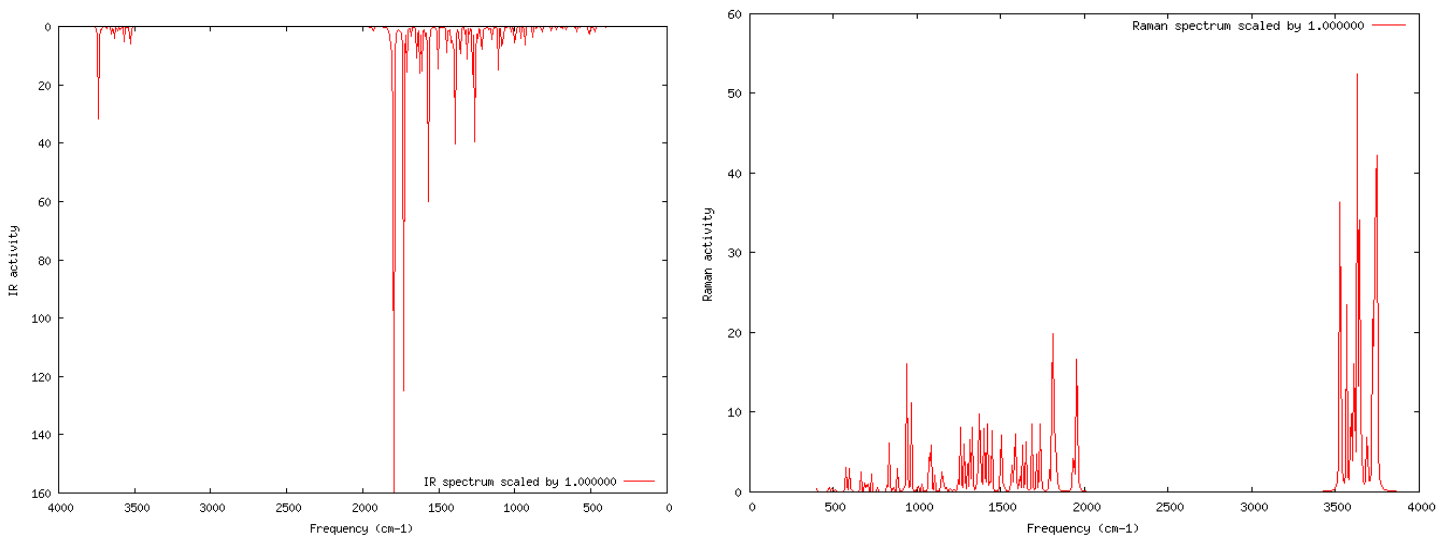

Figure 4 (b) Observed FT-IR and FT-Raman Spectra of Cubebin

Table.1: Frontier molecular orbital's energies $(\mathrm{eV})$ and energy gap $(\mathrm{eV})$ for studied dyes using 6-11++G $* *$ level of theory.

\begin{tabular}{|c|c|c|c|}
\hline Compound & HOMO (eV) & LUMO (eV) & Energy gap in \\
\hline Betalain & -4.75 & -1.95 & 2 \\
\hline Cubebin & -4.52 & -1.63 & 2 \\
\hline
\end{tabular}

Ranjitha et al., 
A D- $\pi$-A dye with a stronger electron-donating group should give a high HOMO when compared to that of electrolyte and conduction band of semiconductor (TiO2). The electron distribution of HOMO is mainly located in the electro-donor to the $\pi$-conjugated linker while subjecting to sun light irradiation and the electron transfer proceeds from the electron-donor to the electron- acceptor through the $\pi$-conjugated linker. The electron distribution of LUMO is delocalized in that with a weaker electron-donor. The calculated HOMO, LUMO and related band gap for dyes are reported in Table 1.

\section{Electronic Absorption Spectra}

The time-dependent density functional theory (TDDFT) method has been performed to calculate the electronic absorption spectra of these dyes. Two major absorption peaks have been obtained for natural dyes in the visible region. Computational analysis has indicated that a dye with stronger electron donating group enhances the HOMO energy as compared to a weaker electron-donating group. Betalain is assigned to the intra-molecular charge transfer band at 670$770 \mathrm{~nm}$ and the Cubebin absorption peak are associated with the $\mathrm{n} \rightarrow \pi$ transition of the entire molecule. The $\pi$-conjugated linkers with electron-withdrawing substituent have been shown to generate a slightly blue-shifted absorption band as compared to those without any substituent. The Benchmark calculations have been performed to evaluate the best functional group for correctly predicting the absorption spectra of the dyes employed in this study, and in particular the low-energy transitions. The excitation energies, oscillator strengths, and the contributing configurations for the most relevant first three states of Betalain and Cubebin dyes using DFT methods with 6-311++ $\mathrm{G}^{* *}$ basis set were reported in Table 2 .

The results showed that the wavelength of the peak maximum $\left(\lambda_{\max }\right)$ of ICT spectra is significantly shifted in Betalain pigment $\lambda_{\max }$ values was calculated to be $725 \mathrm{~nm}, 918 \mathrm{~nm}$ and $1101 \mathrm{~nm}$ respectively. Comparisons between the calculated and experimental spectra of a dye of similar structure of Betalain predicted that $\lambda_{\max }$ obtained from TD-DFT calculation to be $725 \mathrm{~nm}$ in excellent agreement with the experimentally observed value of $670 \mathrm{~nm}$. Furthermore, the calculated absorption wavelengths of Betalain and Cubebin at $6-311++G^{* *}$ level of theory are in good agreement with the corresponding experimental value. Both the natural dyes show intense narrow absorption bands, but as a consequence of the extended $\pi$-system of Betalain, its absorption maximum is shifted to $725 \mathrm{~nm}$ as compared to Cubebin $\left(\lambda_{\max }=250 \mathrm{~nm}\right)$.

The absorption spectra of Betalain shows a strong optically allowed band at $670.25 \mathrm{~nm}$, corresponding to the HOMO/LUMO transition, and a less intense band at $725.87 \mathrm{~nm}$. The absorption spectra display good absorption maxima for Betalain as compared to the corresponding transition in Cubebin irrespective of the DFT functional used. As shown in Table.2 and Figure 5 $(a, b)$ the first absorption band for Betalain is in the near IR region $725.87 \mathrm{~nm}$.

The frontier orbital's (HOMO and LUMO) analyses were paid much attention as they play significant role in the stability of the compounds. Establishment of difference in the energies of the HOMO and LUMO and their band gap in $\mathrm{eV}$ envisages the compounds excitement which fascinates the pigments capability as potential sensitizers. The calculated HOMO and LUMO energy levels and their band gaps in the terms of $\mathrm{eV}$ were reported in the Table.1.

The LUMO of the dyes need to be higher than the conduction band edge of $\mathrm{TiO}_{2}$, for an effective injection of charge into conduction band of $\mathrm{TiO}_{2}$. The computational generated energy levels of HOMO and LUMO of Betalain were $-4.75 \mathrm{eV}$ and $-1.95 \mathrm{eV}$, respectively, where as the energy levels of HOMO and LUMO of Cubebin were $-4.52 \mathrm{eV}$ and $-1.63 \mathrm{eV}$, respectively.

The calculated band gaps of Betalain and Cubebin were $2.70 \mathrm{eV}$ and $2.89 \mathrm{eV}$, respectively (Table 1 ). It is observed the band gap of Betalain is less in comparison with cubebin, which is considered as favorable for efficient absorption of solar energy.

The results of electron distribution of natural transition orbitals (NTO) as reported in Figure.6 and Figure.7 clearly indicate that the studied Betalain and Cubebin dyes are potent sensitizers for DSSCs.

Table 2: Absorption wavelength $(\mathrm{nm})$ and oscillator strength (f) calculated by using 6-311++G** basis set for acceptor dyes.

\begin{tabular}{|c|c|c|c|c|c|c|c|c|}
\hline $\begin{array}{c}\text { BASIS } \\
\text { SET }\end{array}$ & \multicolumn{4}{|c|}{ Betalain Pigment } & \multicolumn{3}{c|}{ Cubebin pigment } \\
\hline & $\begin{array}{c}\text { Wave } \\
\text { length } \\
\text { (nm) }\end{array}$ & F (LHE) & $\begin{array}{c}\text { Mo } \\
\text { contribution }\end{array}$ & $\begin{array}{c}\text { Mo } \\
\text { coefficient }\end{array}$ & $\begin{array}{c}\text { Wave } \\
\text { length } \\
\text { (nm) }\end{array}$ & F (LHE) & $\begin{array}{c}\text { Mo } \\
\text { contribution }\end{array}$ & $\begin{array}{c}\text { MO } \\
\text { coefficient }\end{array}$ \\
\cline { 2 - 9 } & 1101 & 0.0013 & $144->145$ & 0.63 & 251 & 0.1075 & $93->95$ & 0.61 \\
$\begin{array}{l}6-311 \\
++G^{* *}\end{array}$ & 918 & 0.0005 & $143->145$ & 0.24 & 249 & 0.063 & $94->96$ & 0.60 \\
\cline { 2 - 9 } & 725 & 0.0787 & $142->145$ & 0.23 & 245 & 0.0002 & $94->95$ & 0.70 \\
\hline
\end{tabular}




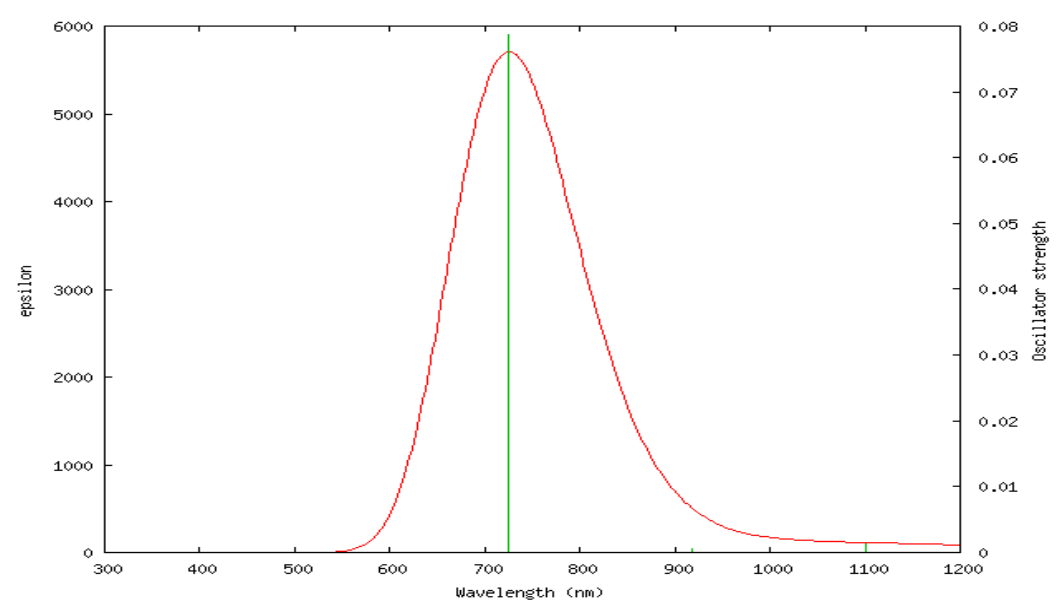

Figure.5a: The UV-Vis absorption spectra of Betalain calculated by $6-311++G^{* *}$ basis set.

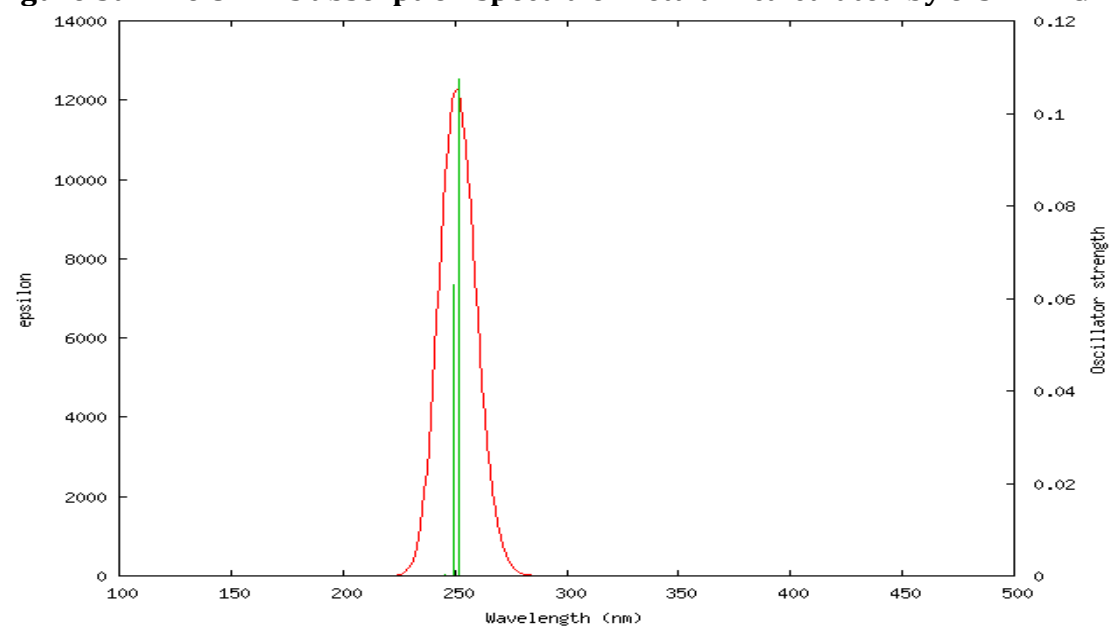

Figure.5b: The UV-Vis absorption spectra of Cubebin calculated by 6-311++G** basis set.

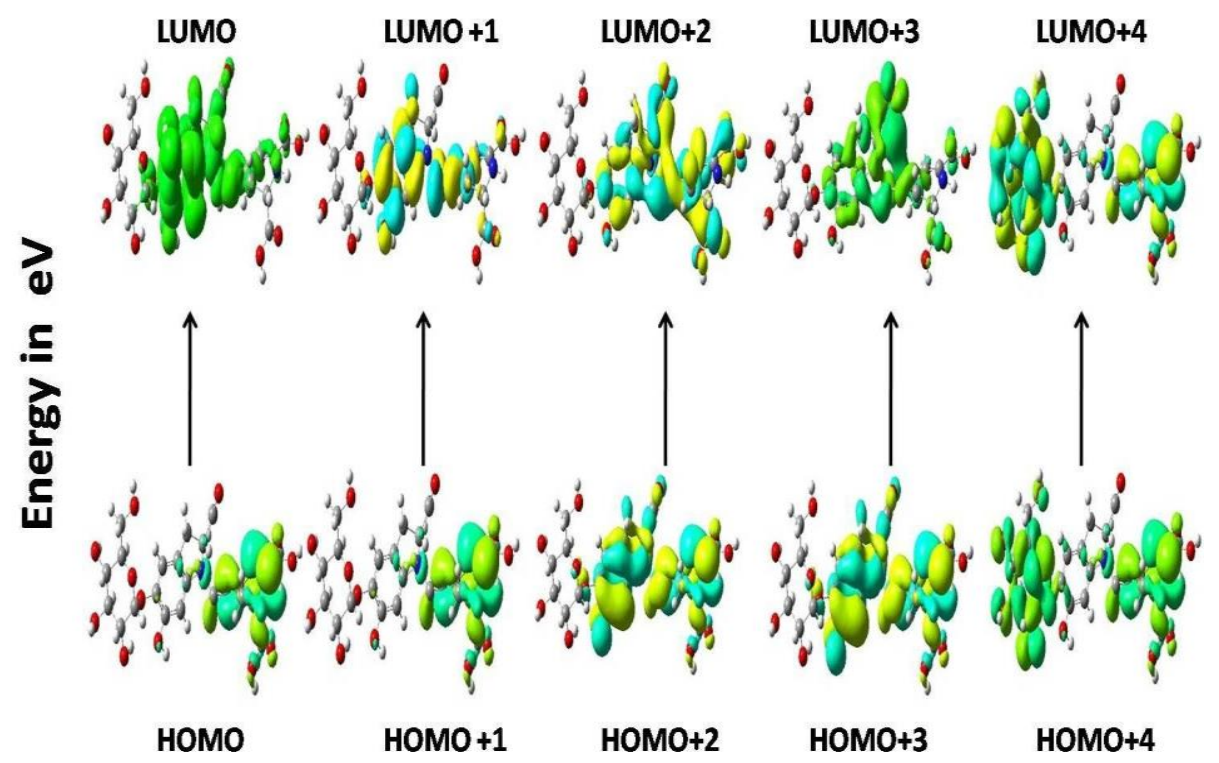

Figure 6: Schematic diagram of the NTO's of Betalain calculated at the $6-311++G^{* *}$ level of theory. The surfaces are generated with an isovalue at 0.02

Ranjitha et al., 


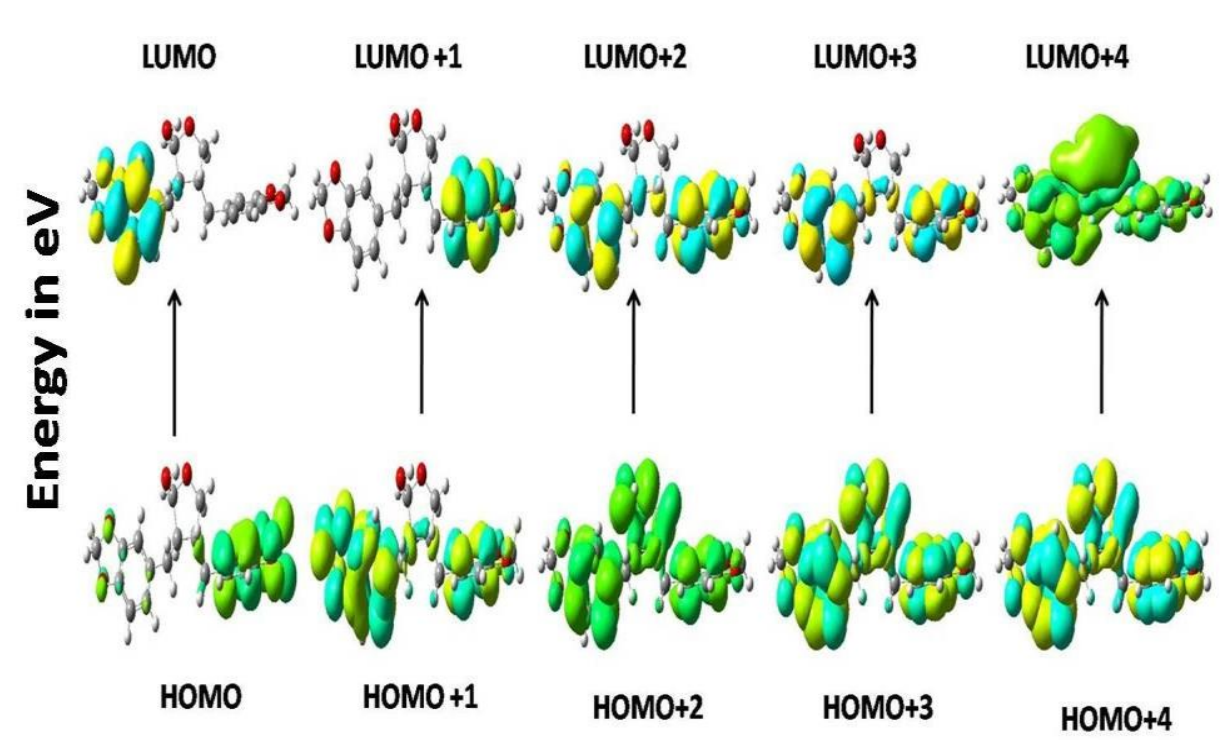

Figure 7: Schematic diagram of the NTO's of Cubecubin calculated at the 6-311++G** level of theory. The surfaces are generated with an isovalue at 0.02

The movement of electron charge density distributed mainly on the donor units before light irradiation and to the acceptor units after light irradiation favors the electron injection from dye molecules to the conduction band edge of $\mathrm{TiO}_{2}$. It is observed that the electron density moves from donor moiety towards the anchoring group in all the transitions of both Betalain and Cubebin dyes. This feature of dyes results in directional electron transfer to the conduction band of $\mathrm{TiO}_{2}$. The anchoring group in Betalain and Cubebin exhibited considerable contribution to the LUMOs which lead to a strong electronic coupling with $\mathrm{TiO}_{2}$ surface thus improved the electron injection efficiency. This would subsequently enhances the short-circuit current density Jsc. Thus the resulting excited states of both dyes are strongly coupled to the $\mathrm{TiO}_{2}$ surface due to charge delocalization involving the anchoring hydroxyl group.

The NTO orbitals of all transitions computed for Betalain and Cubebin are included in Figure 6 and 7 based on the TD-DFT calculation at $6-311++\mathrm{G}^{* *}$ level of theory. The NTO analysis yields an unambiguous donor-acceptor pair for most cases, thus facilitating the assignment of the nature of the electronic transition. The most prominent transitions in UV-Vis range have been analyzed. It can be clearly seen that HOMO is localized to a great extent on the Betalain core, which is associated with the $\pi$-framework of the Betalain ring. One can notice a similar pattern for the charge density distribution in the NTO's of both Betalain and Cubebin. It is interesting to note that in the excited state there is a clear charge transfer towards the acceptor moiety. In Betalain, there is a further clear accumulation of charge on the anchoring group. This charge accumulation has a pronounced effect in the charge injection into the CB of the electrode. TD-DFT calculations on Cubebin dye (Table 2) reveal an intense absorption at $250.25 \mathrm{~nm} \quad(\mathrm{f}=0.613)$ associated with the $\pi-\pi^{*}$ electronic transition. This transition corresponds to excitation from HOMO-LUMO responsible for the facile charge flow from the cubebin core to the anchoring group. As discussed, in these transitions the initial states are mainly related to the MOs that are localized on electron donor groups, while the final states are mainly related to the MOs that are localized on electron acceptor groups. This indicates that the absorptions are photo induced electron transfer processes, thus the excitations generated were the charge separated states. It is instructive at this point to attempt an estimation of the light harvesting efficiency of the dyes under investigation. LHE can be computed using equation (1)

$$
\text { LHE }=1-10^{-\mathrm{f}}
$$

Where, $\mathrm{f}$ is the computed oscillator strength of the electronic transition. The computed LHE values are listed in Table. 3 for the first $n-\pi^{*}$ transition for both Betalain and Cubebin. This photo physical property reveals the electron density to concentrate on the electron-donor, which is the main chromophore responsible to the sensitization of photo-to-current conversion processes. The results of this theoretical investigation will help to design and develop more efficient natural dyes for the DSSC applications.

\section{Photovoltaic Performance}

Current-voltage curve measurements are the most central way to characterize the photovoltaic (PV) device performance. The solar cell efficiency is determined by its current-voltage (I-V) characteristics under standard illumination conditions. A standard solar spectrum of air mass 1.5 (AM 1.5) with an intensity (the power of incident light) of $100 \mathrm{~m} \mathrm{~W} / \mathrm{cm}^{2}$ also referred to as 1 sun, is used for solar cell characterization. The performance of dye-sensitized solar cells was evaluated in terms of short circuit current density $J_{\mathrm{SC}}$, open circuit voltage $V_{\mathrm{OC}}$, fill factor $F F$ and efficiency $\eta \%$ which are shown in Table 3 and the Current -Voltage curve in

\section{Ranjitha et al.,}




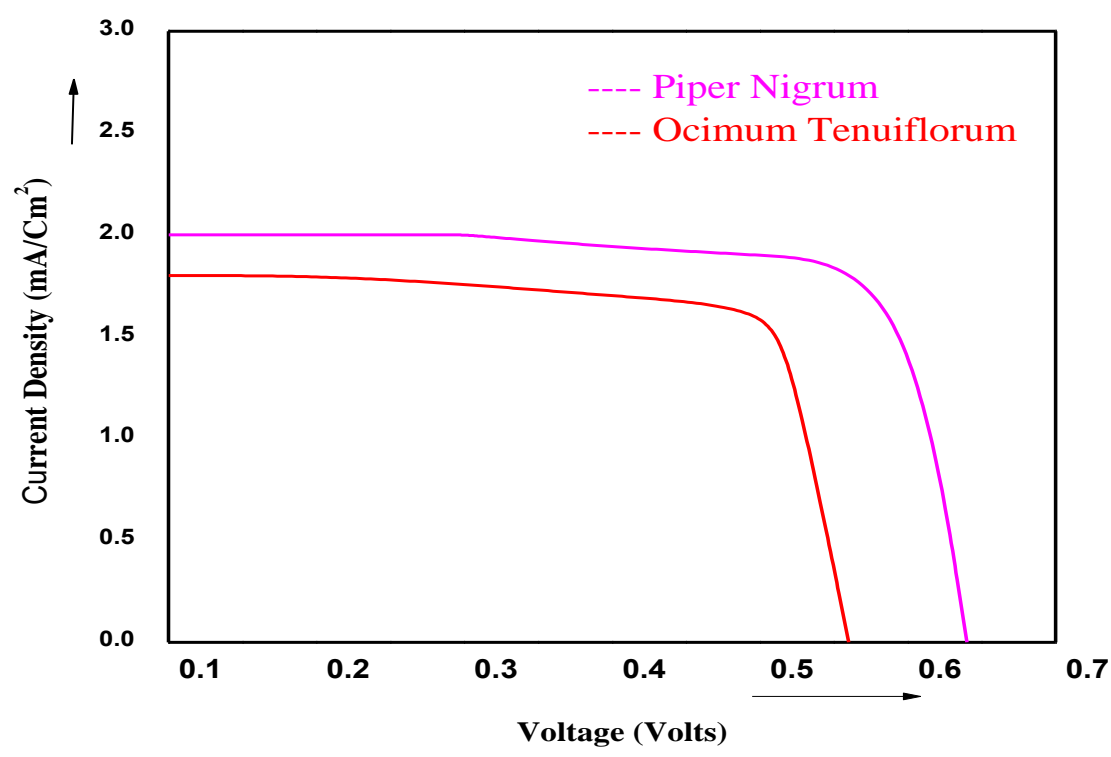

Figure 8. Current -Voltage characteristics of Piper nigrum and Ocimum tenuiflorum

Table.3: Characteristics of DSSC

\begin{tabular}{|c|c|c|c|c|c|c|}
\hline $\begin{array}{l}\text { Name of the } \\
\text { Photosensitizer }\end{array}$ & $\begin{array}{l}\text { JSc } \\
\text { (mA }\end{array}$ & $\begin{array}{l}\text { Voc } \\
(\mathrm{mV})\end{array}$ & FF & $\eta \%$ & \multicolumn{2}{|c|}{ References for comparison of $\eta \%$} \\
\hline \multirow{4}{*}{ Piper Nigrum } & \multirow{4}{*}{1.8} & \multirow{4}{*}{0.56} & \multirow{4}{*}{0.725} & \multirow{4}{*}{0.392} & $\begin{array}{l}\text { Beta Betaxanthin } \\
\text { Betanin }\end{array}$ & $\begin{array}{l}0.19 \text { (Ref 26) } \\
0.07\end{array}$ \\
\hline & & & & & $\begin{array}{l}\text { Water extract (hydrochloric } \\
\text { acid) }\end{array}$ & $0.119(\operatorname{Ref} 30)$ \\
\hline & & & & & $\begin{array}{c}\text { Water extract (HCL) } \\
\text { Water extract (ascorbic acid) }\end{array}$ & $\begin{array}{l}0.402 \\
0.106\end{array}$ \\
\hline & & & & & $\begin{array}{l}\text { Purified methanol extract } \\
\text { (hydrochloric acid) }\end{array}$ & 0.048 \\
\hline $\begin{array}{l}\text { Ocimum } \\
\text { Tenuiflorum }\end{array}$ & 1.72 & 0.5 & 0.797 & 0.38 & & \\
\hline
\end{tabular}

The fill factor and efficiency were calculated under a stimulated illumination with a light intensity of 100 $\mathrm{mW} / \mathrm{cm}^{2}$. The FF of the DSSC was calculated using the equation,

$$
F F=I_{\max } V_{\max } / I_{S C} V_{S C}
$$

The incident photon - to - current (IPCE)

efficiency ( $)$ ) was calculated using the equation $\eta \dot{\eta}(\%)=I \max$

$$
V_{\text {max }} / P_{\text {inc }}
$$

Where $I_{\max }$ and $V_{\max }$ are the current and voltage obtained at the maximum power point on the photovoltaic power output curve and $\mathrm{P}_{\mathrm{in}}$ is the power density of the incident radiation respectively. In principle, the maximum $\mathrm{I}_{\mathrm{SC}}$ of a dye-sensitized solar cell is determined by how well the absorption window of the dye overlaps with the solar spectrum. The overall photo conversion efficiency $(\eta)$ is calculated from the integral photocurrent density ( $\mathrm{J}_{\mathrm{Sc}}$ ), the open circuit photocurrent $\left(\mathrm{V}_{\mathrm{OC}}\right)$, the fill factor $(\mathrm{FF})$ of the cell, and the intensity of the incident light (Pin).

It is clearly shown in the Table 3 that there is a close resemblance of the photo current conversion efficiency curve with the absorption spectrum of the respective dye providing clear evidence of the sensitization of photocurrent. In this study, among the two natural dyes, the betalain dye extracted from the Ocimum tenuiflorum is shown to be promising dyes for photovoltaic's. The solar conversion efficiency of the dye based DSSC sensitized from Ocimum tenuiflorum can reach $0.392 \%$ under irradiation of $100 \mathrm{~mW} / \mathrm{cm}^{2}$, which is the highest photo signal in this study. These two natural photosensitizers applied in $\mathrm{TiO}_{2}$ based DSSC are thus suitable to improve the efficiency of ecofriendly energy devices. The efficiency of natural dye-

Ranjitha et al., 
sensitized solar cells is determined by a number of factors that include selection of the appropriate natural dye, quantitatively significant stable electronic anchorage of the dye to the surface of the metal oxide nanostructure, choice of photo anode, counter electrodes, electrolyte and solvent system. It is therefore highly desirable to standardize these critical factors in the context of making natural dye-sensitized solar cells a commercially viable option. The advantages of natural dyes as photo sensitizer are large absorption coefficients, high light- harvesting efficiency, no resource limitations, low cost, simple preparation techniques and ecofriendly. Although the efficiencies obtained with these natural dyes are still below the current requirements for large scale practical applications, these interesting explorations of fabrication of dye-sensitized solar cell using dyes obtained from bio-resources invoked participation of researchers around the globe to engage in research to search for new sources of natural dye systems that are stable, non-toxic, biocompatible and have desirable optoelectronic properties. Some serious efforts in natural dye sensitizers may spring up a perspective of commercial feasibility for inexpensive and environmentally friendly dye-sensitized solar cells.

\section{CONCLUSION}

As the DSSC are the promising alternative for the development of new generation solar cells, the use of natural pigments has become a viable alternative resource for the development of third generation solar cells. In this work we report that the successful conversion of visible light into electricity was achieved by employing the dyes Betalain and cubecin extracted from Ocimum tenuiflorum and Piper nigrum. These extracted dyes were characterized by UV-Vis absorption spectra, Photoluminescence and photo electrochemical properties of the DSSC. I-V characteristics curves were measured and the photo electrochemical properties were investigated. The highest efficiency was obtained for DSSC fabricated with $\mathrm{Ti}_{2}$ sensitized by Betalain dye extracted from Ocimum tenuiflorum.

\section{REFERENCES}

[1]. Awodibo Michael, Boyo Adenike, Oluwole Surukite, Abudusalami Ibrahim and Boyo Henry., 2013, Construction of Dye Sensitized Solar Cell with Bouganvilla,Cordia Sebestena and Talinium Triangulare Flower, Journal of Natural Sciences Research. 3, 5-10.

[2]. Cherepy, N. J., G.P. Smestad, M. Gratzel and J. Z. Zang., 1997. Ultrafast Electron Injection: Implications for a Photoelectrochemical Cell Utilizing an Anthocyanin Dye-Sensitized $\mathrm{TiO}_{2}$ Nanocrystalline Electrode, J. Phys. Chem.B, 101:9342-9351.

[3]. Efurumibe,E.L., Asiegbu, A.D., Onuu,M.U., 2012, Mathematical modelling of electron transport through the anode $\left(\mathrm{TiO}_{2}\right)$ of a standard dyesensitized solar cell Asian J. Applied Sci. 5:33-42.
[4]. Gratzel, M., 2004. Dye-sensitized solar cells, Journal of Photochemistry and Photobiology C: Photochemistry Reviews, 4:145-153.

[5]. Hao, S., J. Wu, Y. Huang and J. Lin., 2006. Plant Seeds-Based Dye-Sensitized Solar Cells, Solar Energy, 80: 209-214.

[6]. Idu, M. and H. I. Onyibe., 2007. Medicinal plants of Edo State, Nigeria. Res. J. Med.Plant, 1: 32-41.

[7]. Chou,C.S., Chou,F.C., Kang, J.Y., 2012. Preparation of $\mathrm{ZnO}$-coated $\mathrm{TiO}_{2}$ electrodes using dip coating and their applications in dyesensitized solar cells, Powder Technology, 215216, 38-45.

[8]. Senthil, T.S., Muthukumarasamy, N., Velauthapillai, D.,Agilan, S.,Thambidurai,M., Balasundaraprabhu, R., 2011, Natural dye (cyanidin 3-0-glucoside) sensitized nanocrystalline $\mathrm{TiO}_{2}$ solar cell fabricated using liquid electrolyte/quasi-solid-state polymer electrolyte, Renewable Energy, 36(9), 2484-2488.

[9]. Ratna Chauhan, Reena Kushwaha, and Lal Bahadur, 2011. Study of Light Harvesting Properties of Different Classes of Metal-Free Organic Dyes in $\mathrm{TiO}_{2}$ Based Dye-Sensitized Solar Cells, International Journal of Photo energy, 2011, 9-12.

[10]. Kanmani,S.S., Ramachandran, K., 2012. Synthesis and characterization of $\mathrm{TiO}_{2} / \mathrm{ZnO}$ core/shell nanomaterials for solar cell applications, Renewable Energy, 43, 149-156.

[11]. Michael, A., Adenike,B., Surukite, O., Ibrahim, A., Henry, B, 2013, Construction of Dye Sensitized Solar Cell with Bouganvilla,Cordia Sebestena and Talinium Triangulare Flower, Journal of Natural Sciences Research 3 (5)13-24.

[12]. O’Regan,B., Gratzel, M., 1991., A Low-Cost, HighEfficiency Solar Cell Based on Dye-Sensitized Colloidal TiO2 Films. Nature, 353, 6346, 737-740.

[13]. Kamat, P.V., Schatz, G.C., 2009, Nanotechnology for next generation solar cells. Journal of Physical Chemistry C, 113(35), 15473-15475.

[14]. Jiao,T.F., Wang, Y., Zhang, Q. R, 2013, Preparation and photocatalytic property of gold nanoparticles by using two bolaform cholesteryl imide derivatives,, Journal of Dispersion Science and Technology, 34(2), 1675-1682.

[15]. C. Sandquist, J.L. McHale, Improved efficiency of betanin-based dye-sensitized solar cells, Journal of Photochemistry and Photobiology A 221 (2011),90-97.

[16]. Fernando., J.M.R.C., Senadeera, G.K.R., 2008, Natural anthocyanins as photo sensitizers for dye sensitized solar cells, Current Science, 95(5):663666.

[17]. Mark A. Kelm and Muraleedharan G. Nair. Mosquitocidal Compounds and a Triglyceride, 1,3Dilinoleneoyl 2-palmitin, from Ocimum sanctum, J.Agric. Food Chem., 1998, 46 (8), 3092-3094,

[18]. Bhawana Rathi, Sameksha Koul, R. L Khosa (2013). Journal of Natural Remedies, 23203358, Vol 13. 
[19]. Polo, A.S., Iha, N.Y.M., 2006, Blue sensitizers for solar cells: natural dyes from Calafate and Jaboticaba Journal of Solar Energy Materials and Solar Cells, 80, 209-214.

[20]. Feng, J., Jiao, Y., Ma, W., Nazeeruddin,M.K. Grätzel, M., Meng,S., 2013, First principles design of dye molecules with ullazine donor for dye sensitized solar cells, The Journal of Physical Chemistry C, 117 (8) 3772-3778.

[21]. Chen, Z., Li,F., Huang,C., 2007, Current Organic Chemistry, Organic D- $\pi$-A dyes for dye-sensitized solar cell, Current Organic Chemistry, 11(14), 1241-1258.

[22]. Ranjitha, S., Aroulmoji,V., Mohr, T., Anbarasan, P.M., Rajarajan, G., 2014. Structural and spectral properties of 1 2-dihydroxy-9 10-anthraquinone Dye Sensitizer for Solar Cell Applications, Acta Physica Polonica A 126: 6. 833-839 9.

[23]. Mohr,T., Aroulmoji, V., Samson Ravindran,R., Müller, M., Ranjitha, S., Rajarajan, G., Anbarasan, P.M., 2014. DFT and TD-DFT study on Geometries, Electronic Structures and Electronic Absorption of Some Metal Free Dye Sensitizers for Dye Sensitized Solar Cells, Spectrochim Acta A Mol Biomol Spectroscopy 135: 1066-1073.

[24]. Ranjitha, S, Rajarajan, G, Gnanendra, T.S, Anbarasan, P.M., Aroulmoji, V., 2015 Spectrochimica Acta Part A: Molecular and Biomolecular Spectroscopy, 149(5) 997-1008.
[25]. Matsuda, H., Kawaguchi, Y., Yamazaki, M., Hirata, N., Naruto, S., Asanuma, Y. Kaihatsu, T.Kubo, M., 2004. Melanogenesis Stimulation in Murine B16 Melanoma Cells by Piper nigrum Leaf Extract and Its Lignan Constituents, Biological \& Pharmaceutical Bulletin, 27(10), 1611-1616.

[26]. Dongshe Zhang a, Suzanne M. Lanier a, Jonathan A. Downing a,ason L. Avent a,b, June Lumc, Jeanne L. McHalea,2008, Betalain pigments for dyesensitized solar cells, Journal of Photochemistry and Photobiology A: Chemistry 195, 72-80

[27]. Liu, T.M., Chu,S.W., Sun, C.K., Lin,B.L., Cheng,P.C., Johnson,I., 2001, Multi- photon confocal microscopy using a femtosecond Cr:forsterite laser. Scanning 23, 249- 254.

[28]. Shimatani, K., Tajima, H., Komino, T., Ikeda, S., Matsuda, M., 2005. The electroluminescence spectrum of chlorophyll a, Chem. Lett.34, 948.

[29]. Geetha,M., Suguna, K., Anbarasan, P.M., Aroulmoji, V., 2014, Preparation and Characterization of Tailored $\mathrm{TiO}_{2}$ Nano Particles Photoanode for Dye Sensitized Solar Cells, International journal Advanced Science \& Engineering,1(1), 1-5.

[30]. Corneliu I. Opreaa, Anca Dumbravab, Irina Enacheb,c, Adrian Georgescua, Mihai A. Girtu, 2012, A combined experimental and theoretical study of natural betalain pigments used in dyesensitized solar cells, Journal of Photochemistry and Photobiology A: Chemistry 240 (2012) 5- 13. 